\title{
A Novel Fusion Model for Battery Online State of Charge (SOC) Estimation
}

\author{
Yufang $L i^{12, *}$, Guofang $X u^{1}$, Bingqin Xu ${ }^{1}$, Yumei Zhang ${ }^{1}$ \\ ${ }^{1}$ Department of Vehicle Engineering, College of Energy \& Power Engineering, Nanjing University of \\ Aeronautics and Astronautics, Nanjing 210016, China \\ ${ }^{2}$ Key Laboratory of Advanced Manufacture Technology for Automobile Parts (Chongqing University \\ of Technology), Chongqing 400054, China \\ *E-mail: 1yf2007@nuaa.edu.cn
}

doi: $10.20964 / 2021.01 .76$

Received: 2 October 2020 / Accepted: 16 November 2020 / Published: 30 November 2020

The state of charge (SOC) is a key parameter in battery management systems (BMSs). As an indirect parameter, accurately estimating the SOC has been an area of interest in battery research. To achieve online SOC estimation under variable temperature and discharge rate conditions, this paper proposes a novel modeling methodology for battery online SOC estimation based on an extended Kalman filter (EKF) and a backpropagation (BP) neural network and a method for calculating the true value of the battery SOC under these varying conditions for model validation. Three types of SOC estimation models are established and compared, involving an EKF model based on a second-order equivalent circuit model, a data-driven BP neural network model, and a fusion of the two models. Ultimately, the validity and rationality of the fusion modeling methodology for SOC online estimation proposed in this paper is verified by experimental data.

Keywords: SOC estimation, fusion modeling, EKF, BP, variable operating conditions

\section{$\underline{\text { FULL TEXT }}$}

(C) 2021 The Authors. Published by ESG (www.electrochemsci.org). This article is an open access article distributed under the terms and conditions of the Creative Commons Attribution license (http://creativecommons.org/licenses/by/4.0/). 